\title{
Study on oil displacement efficiency of offshore sandstone reservoir with big bottom water
}

\author{
Jie $\operatorname{Tan}^{1}\left[10\right.$ - Ying-xian Liu ${ }^{1} \cdot$ Yan-lai Li ${ }^{1}$ Chun-yan Liu' ${ }^{1}$ Song-ru Mou ${ }^{1}$
}

Received: 4 December 2020 / Accepted: 27 May 2021 / Published online: 11 June 2021

(c) The Author(s) 2021

\begin{abstract}
$\mathrm{X}$ oilfield is a typical sandstone reservoir with big bottom water in the Bohai Sea. The viscosity of crude oil ranges from 30 to $425 \mathrm{cp}$. Single sand development with the horizontal well is adopted. At present, the water content is as high as $96 \%$. The water cut of the production well is stable for a long time in the high water cut period. The recoverable reserves calculated by conventional methods have gradually increased, and even the partial recovery has exceeded the predicted recovery rate. This study carried out an oil displacement efficiency experiment under big water drive multiple to accurately understand an extensive bottom water reservoir's production law in an ultra-high water cut stage. It comprehensively used the scanning electron microscope date, casting thin section, oil displacement experiment, and production performance to analyze the change law of physical properties and relative permeability curve from the aspects of reservoir clay minerals, median particle size, pore distribution, and pore throat characteristics. Therefore, the development law of horizontal production wells in sandstone reservoirs with big bottom water is understood. It evaluates the ultimate recovery of sandstone reservoirs with big bottom water. It provides a fundamental theoretical basis and guidance for dynamic prediction and delicate potential tapping of sandstone reservoirs with big bottom water at a high water cut stage.
\end{abstract}

Keywords Big bottom water reservoir $\cdot$ Extra-high water cut stage $\cdot$ Ample water drive multiple $\cdot$ Oil displacement efficiency

\section{Introduction}

\section{Preface}

$\mathrm{X}$ oilfield is a typical sandstone reservoir with big bottom water in the Bohai Sea. The viscosity of crude oil ranges from 30 to $425 \mathrm{cp}$. It is mainly driven by natural water. At present, the water content is as high as $96 \%$. The water cut of the production well is stable for a long time in the high water cut period. At present, this kind of reservoir is mainly developed by horizontal wells with large liquid volumes. The following problems are encountered in the development process: the water cut of horizontal wells increases rapidly after the bottom water breakthrough, but the water cut of production wells is stable for a long time after reaching the high water cut stage. As a result, the recoverable reserves

Jie Tan

4687610@qq.com

1 Bohai Oilfield Research Institute, Tianjin Branch of CNOOC Ltd, Tianjin, China calculated by the water drive curve gradually increase, and the current local recovery degree of some wells has exceeded the predicted recovery rate. The conventional relative permeability curve cannot describe the law of water injection in the ultra-high water cut stage.

The water drive oilfield's ultimate recovery factor symbolizes the utilization of underground resources, an essential basis for oilfield development decisions, and an essential embodiment of the oilfield development level. The final recovery factor is the product of displacement efficiency and sweep volume factor. Therefore, the factors that affect water flooding efficiency and sweep volume coefficient affect water drive recovery. The efficiency of water flooding mainly depended on geological and fluid properties, such as reservoir type, reservoir heterogeneity, rock wettability, and crude oil viscosity.

At present, there are much researches on the influence of various factors on water flooding efficiency.

In the aspect of the influence of rock wettability on oil displacement efficiency, some studies show that the wettability of reservoir rock is the main factor determining the

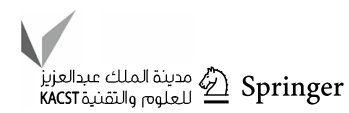


distribution position, flow state, and distribution of fluid in porous media and reservoir wettability has a particular influence on water displacement efficiency (Donaldson et al. 1971; Anderson 1987; Jadhunandan et al. 1995). Before the water breakthrough, the oil displacement efficiency of the hydrophilic core is higher than that of the hydrophilic core. The oil displacement efficiency of weak hydrophilic samples is higher than that of hydrophilic solid samples (Xianmin et al. 1994). When the wettability is transformed from strong hydrophilic to near neutral wetting, the efficiency of water flooding increases (Morrow 1990), and some studies show that the weak hydrophilic rock sample with Amott wettability index of 0.20 can obtain the highest oil displacement efficiency (Jienian 1998).

In terms of the influence of pore structure on oil displacement efficiency, some scholars connect pore structure parameters with conventional parameters of sedimentary environment and sandstone and use the mercury injection method to obtain the relationship between ultimate recovery and characteristic structural parameters (Zhetan and Yuncheng 1986; Puhua and Fangtian 1998, Youfu and Ying 1999). There is an inverse relationship between pore structure coefficient and displacement efficiency (Pingping 2000). It is considered that there is an excellent linear relationship between core mercury injection data and heterogeneity of pore structure (Zhong 2000). Based on thin-section data, the effects of microheterogeneity and pore throat geometry on the formation of remaining oil and displacement efficiency were studied (Bolin 2003, Shaodong 2002, Min 2003; Qiuxuan and Yongli 1996, Yanzhang 1998).

In the influence of permeability on oil displacement efficiency, experiments and oilfield production practice show that when the permeability is more significant than $200 \times 10^{-3} \mu \mathrm{m}^{2}$, its value on oil displacement efficiency is not apparent. When the permeability is minor than $50 \times 10^{-3} \mu \mathrm{m}^{2}$, this influence cannot be ignored (Daopin 1997). It is found that when the crude oil is a Newtonian fluid, the higher the permeability is, the higher the displacement efficiency is. However, oil displacement efficiency is not always positively correlated with permeability (Nailin and Lihua 1997).

In terms of the influence of crude oil viscosity on oil displacement efficiency, the researchers analyzed the variation characteristics of oil displacement efficiency of 25 representative water drive sandstone oilfields in water drive development. They found that crude oil viscosity is the most critical factor affecting the ultimate oil displacement efficiency (Qitai et al. 1989). The oil displacement efficiency is negatively correlated with the logarithm of crude oil viscosity, and the crude oil viscosity and its corresponding fingering are also important factors affecting the oil displacement efficiency (Wensheng 2003). It is found that when the crude oil viscosity is low, the flow resistance is small, and the micro-sweep efficiency and ultimate recovery are high (Renxiong 1995, Yongli 1996).
As for the influence of displacement pressure on oil displacement efficiency, the research shows that increasing water displacement pressure in different production stages is beneficial to improving water displacement efficiency and liquid production rate in low permeability reservoirs (Guo et al. 2004). The increase in displacement pressure can improve oil displacement efficiency initially, but with little effect at the later stage (Wei and Xiaoyan 1999). For weakly hydrophilic neutral and weakly hydrophilic reservoirs, increasing water injection pressure increases water displacement efficiency by about $10 \%$. The displacement efficiency of gradual pressure increase is about $10 \%$ higher than that of sudden pressure increase (Xiaojuan et al. 2005).

In the influence of injection multiple on oil displacement efficiency, the statistical analysis shows that the water flow through the high permeability interlayer is much higher than the average injection multiple of the reservoir in the mixed wetting (partial oil affinity) water drive reservoir profound heterogeneity. The recovery rate of the high permeability interlayer can reach $80 \sim 90 \%$, which is far higher than the indoor $40 \%$ water drive efficiency. The core displacement efficiency increases with the increase in injection times. It is observed that when the water cut reaches $99.98 \%$, the oil displacement efficiency can still be improved by increasing the injection times (Yushuang et al. 1999; Yarveicy et al. 2018; Yarveicy and Javaheri 2019).

There are many types of research on the single factor affecting oil displacement efficiency and the calculation method of ultimate oil displacement efficiency from the research status quo. However, some conclusions of a single factor are contradictory, and there is no universally recognized law. Moreover, there are few reports on the study of displacement efficiency and sweep law in different stages. In this paper, through the systematic study of permeability and relative permeability curves before and after water flooding under different oil-water viscosity ratios, the change laws of reservoir physical properties and relative permeability curves are analyzed, including horizontal wells in sandstone reservoir with big bottom water. The ultimate recovery of sandstone with big bottom water is evaluated. It provides a specific theoretical basis and guidance for performance prediction and fine tapping potential of sandstone reservoir with big bottom water in high water cut stage.

\section{Physical simulation of water drive efficiency in the bottom water reservoir}

\section{Experimental parameters and process}

\section{Experimental fluid}

Experimental oil: the viscosity of simulated oil is $30 \mathrm{cp}$ (at $\left.95{ }^{\circ} \mathrm{C}\right), 90 \mathrm{cp}\left(\right.$ at $\left.88{ }^{\circ} \mathrm{C}\right), 150 \mathrm{cp}\left(\right.$ at $\left.74{ }^{\circ} \mathrm{C}\right), 300 \mathrm{cp}$ (at $\left.64{ }^{\circ} \mathrm{C}\right)$, and $425 \mathrm{cp}\left(\right.$ at $\left.52{ }^{\circ} \mathrm{C}\right)$. 
Simulated formation water: Standard brine, salinity $10000 \mathrm{mg} / \mathrm{L}$.

\section{Experimental process}

In this experiment, the core was evacuated to saturate the standard brine, and then, irreducible water was produced by oil flooding, and then, water flooding was carried out continuously at the specified temperature. The salinity of standard brine was $10000 \mathrm{mg} / \mathrm{L}$, and the initial displacement rate was $1.0 \mathrm{~mL} / \mathrm{min}$. The data of the same exit point, cumulative oil production, cumulative water production, displacement rate, and displacement pressure difference at both ends of the core were recorded. The specific steps are as follows:

A. The standard brine with a salinity of $10,000 \mathrm{mg} / \mathrm{L}$ was prepared. After standing for 1 day, it was filtered with a $0.45 \mathrm{um}$ filter membrane and then put into the intermediate container.

B. The core is evacuated and saturated with standard brine using the core evacuation saturation device, and the dry and wet weight is weighed before and after saturation.

C. The core is put into the holder, and the simulated oil is used to displace the core until no water is produced. Then, the oil permeability under the bound water is measured at the experimental temperature.

D. Connect the process, keep the temperature constant for $1 \mathrm{~h}$ according to the experimental temperature, and then, carry out water flooding according to the set displacement rate. Thus, the water breakthrough point, cumulative oil production, cumulative liquid production, displacement velocity, and displacement pressure difference at both ends of the core are accurately recorded.

E. In the early stage of water breakthrough, the time interval should be selected according to oil production. With the decrease in oil production, the time interval should be extended gradually, and the displacement speed should be increased accordingly. The experiment was finished after water injection 2000 times of pore volume.

F. After the experiment, clean up the experimental flow.

\section{The experiment of oil displacement efficiency under significant injection volume multiple under different permeability and viscosity of crude oil}

According to the reservoir's physical properties in the study block, the core is specially selected to carry out the oil displacement efficiency experiment of significant injection volume multiple under different permeability $(970-9050 \mathrm{mD})$ and different crude oil viscosity (30-425cp). As a result, when the water content is $98 \%$, the recovery range is
$28.3-55.5 \%$, and the recovery range of $2000 \mathrm{PV}$ is $62.5 \%$ 77.5\% (see Fig. 1).

Figure 1 shows that when the water content is $98 \%$, the recovery degree of water drive $2000 \mathrm{PV}$ (2000 times pore volume) and the fluidity of crude oil form a power index relationship, which decreases with the decrease in fluidity.

\section{The experiment of oil displacement efficiency with significant injection volume multiple under different permeability}

When crude oil's viscosity is $30 \mathrm{cp}$, the recovery range of loose cores with different permeability ranges is $18.8-29.2 \%$ in the anhydrous period, $50.4-54.4 \%$ in the $98 \%$ water cut period, and $77.2 \%$ in water drive multiple of $2000 \mathrm{PV}$. According to the curve analysis, when the injection multiple is low, the displacement efficiency rises rapidly. However, after the displacement multiple reaches 500PV, the displacement efficiency changes little (see Fig. 2).

Through the analysis of the relationship between displacement efficiency and permeability in different water cut stages in Fig. 3, it is found that under the same crude oil viscosity, the recovery degree in anhydrous stage, recovery degree in $98 \%$ water cut stage, and the logarithm of recovery degree and permeability in 2000PV all have an absolute positive correlation.

\section{The experiment of oil displacement efficiency at significant injection volume multiple under different viscosity of crude oil}

Under different crude oil viscosity, the core's ultimate recovery with the permeability of $5000 \mathrm{mD}$ is $68.8-75.7 \%$ underwater drive multiple of $2000 \mathrm{PV}$. According to the curve analysis, the displacement efficiency increases rapidly when the injection multiple is low. However, after the displacement multiple reaches 500PV, the displacement efficiency changes little (see Fig. 4).

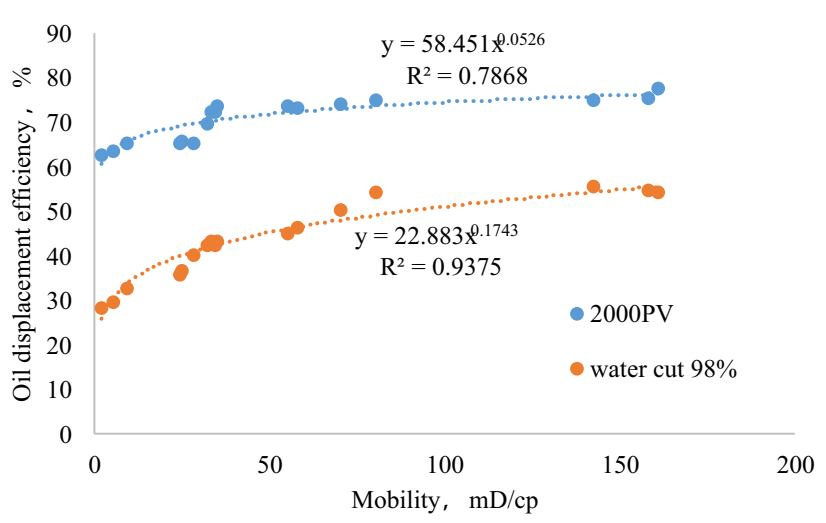

Fig. 1 Oil displacement efficiency curve under different mobility

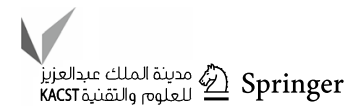




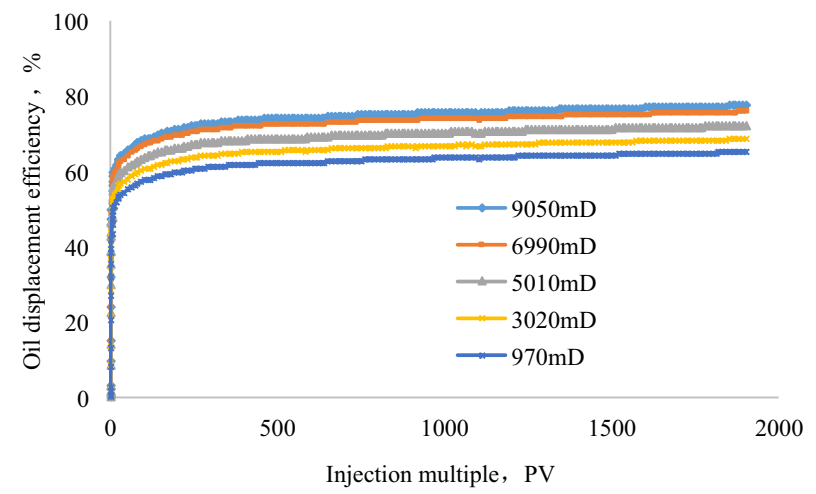

a Curves of injection multiple and displacement efficiency under different permeability

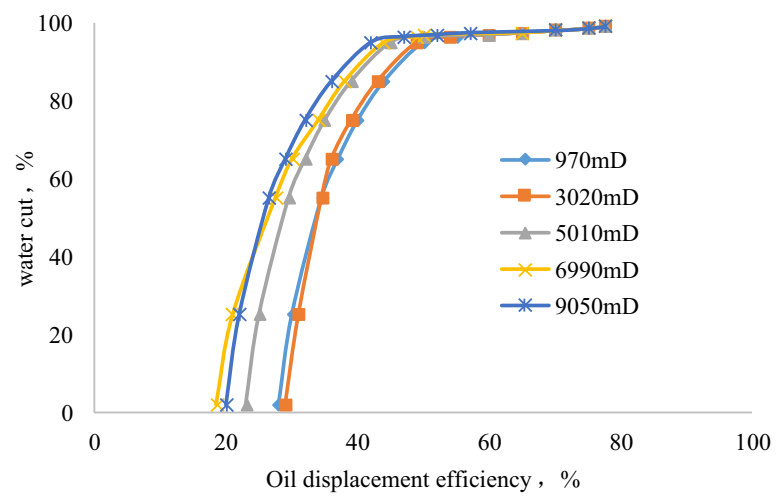

b Curves of water cut and oil displacement efficiency under significant injection multiple

Fig. 2 Curves of injection multiple and displacement efficiency under different permeability. a Curves of injection multiple and displacement efficiency under different permeability; b curves of water cut and oil displacement efficiency under significant injection multiple

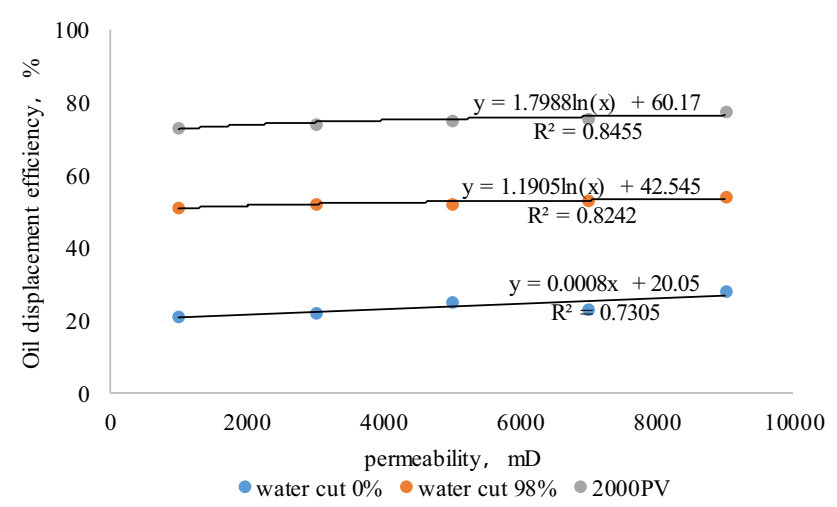

Fig. 3 Relation curves between recovery degree and permeability in different water cut stages

Under different viscosity of crude oil, the range of irreducible water saturation of unconsolidated core with the permeability of $5000 \mathrm{mD}$ is $15.0-20.4 \%$, the range of recovery degree in anhydrous period is $9.3-23.6 \%$, the range of recovery degree in $98 \%$ water cut is $37.0-52.8 \%$, and the limit

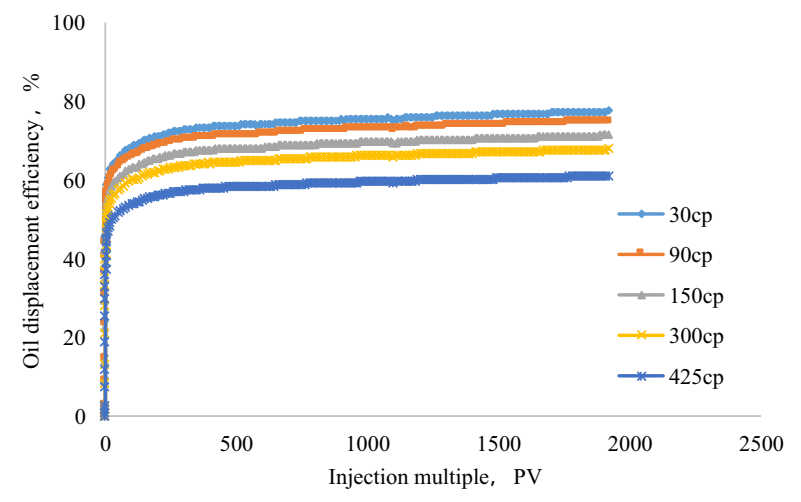

a Curves of injection multiple and displacement efficiency under different viscosity of crude oil

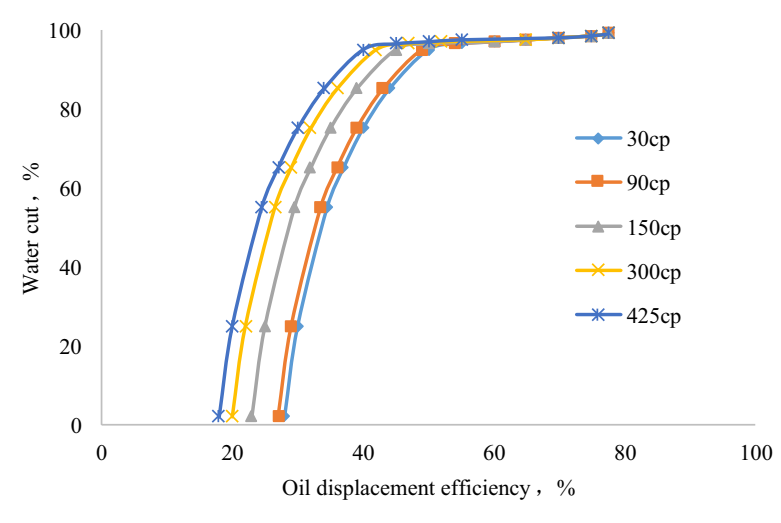

b Oil displacement efficiency curves under different viscosity of crude oil

Fig. 4 Curves of displacement efficiency under different viscosity of crude oil. a Curves of injection multiple and displacement efficiency under different viscosity of crude oil; b oil displacement efficiency curves under different viscosity of crude oil

recovery rate is $72.5-76.5 \%$ underwater drive multiple of 2000PV. According to the curve analysis, the displacement efficiency increases rapidly when the injection multiple is low. However, after the water drives multiple reach 500PV, the displacement efficiency changes little.

Through Fig. 5 analysis of the relationship between oil recovery and crude oil viscosity at different water cut stages when the permeability is $5000 \mathrm{mD}$, it is concluded that the physical properties of the core are similar. However, the recovery degree at the anhydrous stage, recovery degree at $98 \%$ water cut, and the logarithm of ultimate recovery and oil-water viscosity ratio were significantly negatively correlated.

\section{Oil displacement efficiency experiment of significant injection volume multiple under different injection intensity}

The reservoir's physical properties in the block are studied, and the oil displacement efficiency experiments of significant volume multiple under different injection intensities are carried out. According to the oilfield's liquid production, the 


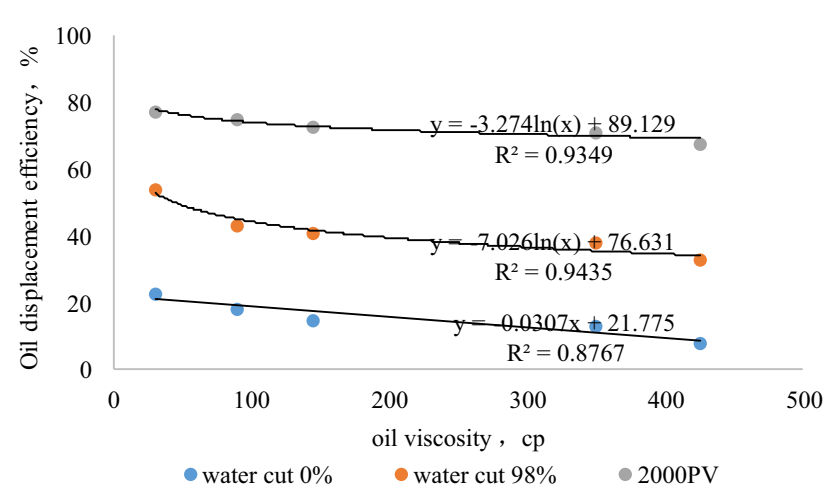

Fig. 5 Relationship between recovery factor and crude oil viscosity in different water cut stages

injection intensity is determined as $0.5 \mathrm{~mL} / \mathrm{min}, 1.0 \mathrm{~mL} /$ $\mathrm{min}$, and $1.5 \mathrm{~mL} / \mathrm{min}$. The experimental results show that the irreducible water saturation of the core decreases with the increase in permeability. As a result, the recovery degree of the core in the anhydrous period ranges from 8.2 to $11.1 \%$, $33.3 \%$ to $36.5 \%$ when the water content is $98 \%$, and 68.7 to $78.8 \%$ when the water content is $2000 \mathrm{PV}$ (see Fig. 6).

According to Fig. 7, when the permeability is $5000 \mathrm{mD}$, the relationship between recovery and injection intensity in different water cut stages is analyzed. It is concluded that: when the physical properties of the core are similar, the recovery degree and injection intensity are negatively correlated in the anhydrous stage, and the recovery degree and ultimate recovery rate are positively correlated with injection intensity in the $98 \%$ water cut stage.

\section{Changes in reservoir physical properties and oil displacement efficiency after long-term water flooding}

The reservoir of $\mathrm{X}$ oilfield is mainly feldspathic quartz sandstone with single lithology; particles support the rock debris, and the particles are sorted as a medium to good, and the skeleton particles are rounded to medium subangular; the cement is mainly clay mineral, carbonate mineral, and a small amount of pyrite. The authigenic minerals in sandstone include clay minerals, calcite, and pyrite. The clay minerals are mainly illite, a mixed layer of Yimeng, kaolinite, and chlorite. The primary clay minerals exist in sandstone in the form of argillaceous fragments. Calcite cementation can be seen in some right areas. The main reservoir types of $\mathrm{X}$ reservoir can be divided into type I and type II (see Table 1).

Conventional physical properties, wettability, casting thin section, X-ray diffraction, scanning electron microscope, mercury injection, and other experimental tests were carried out on the core of sealed coring well in $\mathrm{X}$ reservoir. The

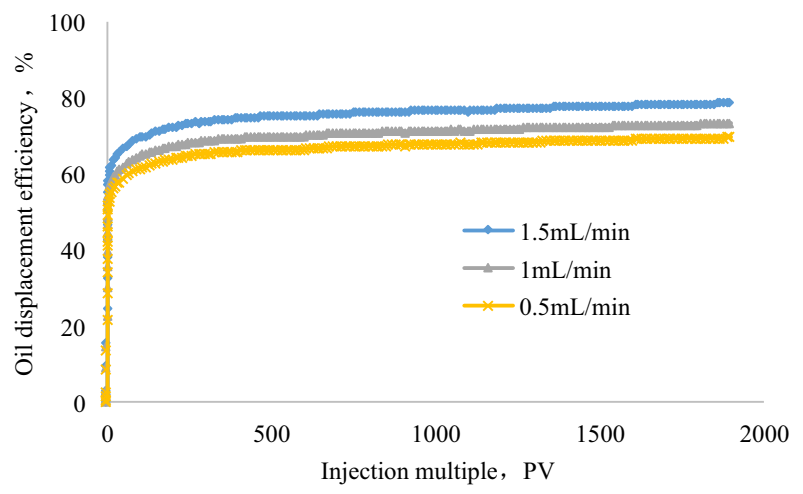

a Oil displacement efficiency curve under different injection intensities

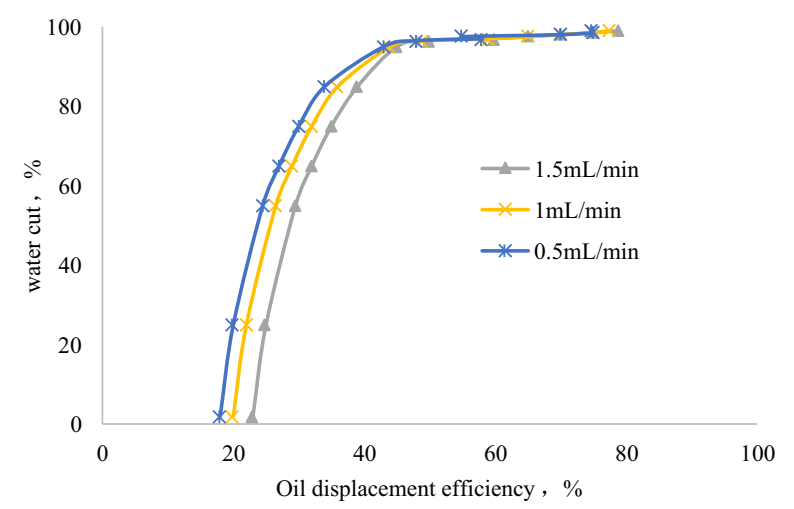

b Curves of water cut and oil displacement efficiency under different injection intensities

Fig. 6 Curves of oil displacement efficiency under different injection intensities. a Oil displacement efficiency curve under different injection intensities; $\mathbf{b}$ curves of water cut and oil displacement efficiency under different injection intensities

changes of physical properties, pore structure, clay minerals, and wettability of the reservoir after long-term water drive were studied by comparing the relevant experimental results of the core of the exploration well.

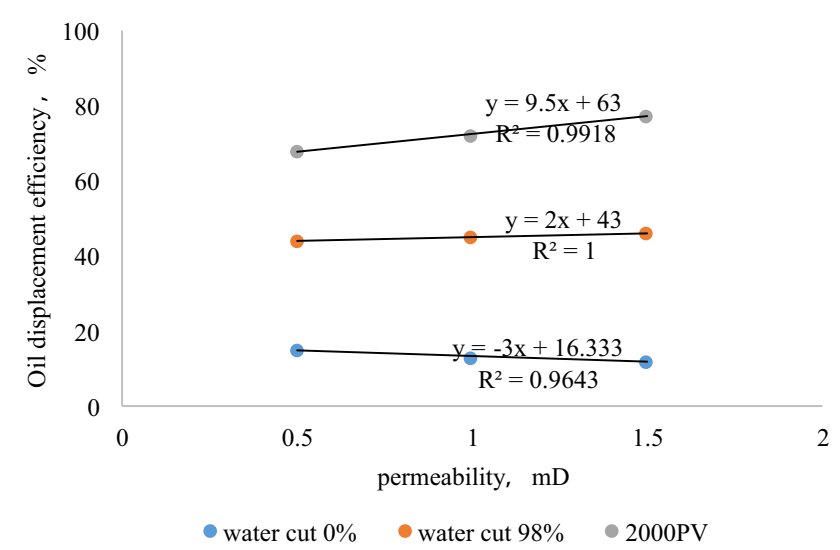

Fig. 7 Relationship between recovery factor and injection intensity in different water cut stages

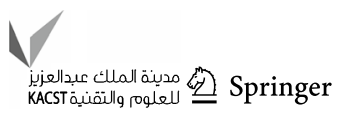




\section{Physical property change of reservoir}

A total of 47 ores of $X$ reservoir were washed with oil and salt after water flooding. Porosity and permeability were retested after drying and weighing. The changes in porosity and permeability before and after water flooding are compared and analyzed. The results show that after long-term water flooding, the permeability changes of reservoirs with different permeability are different. The reservoir with a permeability of more than $3000 \mathrm{mD}$ is the main reservoir with a strong seepage capacity. After long-term washing by the formation water, the permeability increases, and the average permeability increases from 4041 to $6396 \mathrm{mD}$ (see Table 2, Fig. 8). For reservoirs with permeability less than $3000 \mathrm{mD}$, the permeability decreases after long-term formation water scouring, and the average permeability decreases from 1613 to $955 \mathrm{mD}$ (see Table 3, Fig. 8).

\section{Pore structure change of reservoir}

According to the comparison of type I and type II reservoirs, the original rock sample and water drive 2000PV casting thin-section photographs (see Figs. 9-10). It can be seen that the macropore throats are relatively developed before waterflooding in type I reservoir, mainly in the form of long bars or long curved bars, and the mineral particles are in point contact. The roundness is generally sub edge or subcircle-sub-edge, with many intergranular pores and tiny dissolution pores. The pore connectivity is good, and the content of interstitial materials is low. In type I reservoir, after waterflooding $2000 \mathrm{PV}$, the number of macropore throats increases, the number of pore throats decreases, and

Table $1 \mathrm{X}$ reservoir classification evaluation

\begin{tabular}{|c|c|c|c|}
\hline $\begin{array}{l}\text { Petrophysical } \\
\text { facies }\end{array}$ & Lithology & Sedimentary facies & Permeability $\mathrm{mD}$ \\
\hline $\mathrm{I}$ & $\begin{array}{l}\text { Fine to coarse feldspar lithic sandstone. Primary clay minerals (illite, illite, } \\
\text { kaolinite, chlorite) exist in sandstone in the form of argillaceous frag- } \\
\text { ments }\end{array}$ & Meandering river deposit & $\geq 3000$ \\
\hline II & Medium to coarse feldspar lithic sandstone. Calcite cementation & Braided river deposit & $<3000$ \\
\hline
\end{tabular}

Table 2 Changes of physical properties of type I reservoir before and after waterflooding

\begin{tabular}{|c|c|c|c|c|c|c|c|c|c|c|}
\hline \multirow[t]{2}{*}{ Sample ID } & \multirow[t]{2}{*}{ Depth, m } & \multirow[t]{2}{*}{ Length, $\mathrm{cm}$} & \multirow[t]{2}{*}{ Diameter, cm } & \multirow{2}{*}{$\begin{array}{l}\text { Grain } \\
\text { volume, } \\
\mathrm{cm}^{3}\end{array}$} & \multirow{2}{*}{$\begin{array}{l}\text { Grain } \\
\text { density, g/ } \\
\mathrm{cm}^{3}\end{array}$} & \multirow{2}{*}{$\begin{array}{l}\text { Rock } \\
\text { density, g/ } \\
\mathrm{cm}^{3}\end{array}$} & \multicolumn{2}{|c|}{ Before waterflooding } & \multicolumn{2}{|c|}{ After waterflooding } \\
\hline & & & & & & & Porosity, $\%$ & Kair, mD & Porosity, $\%$ & Kair, mD \\
\hline 1-007A & 1258.6 & 2.4 & 2.4 & 7.2 & 2.66 & 1.73 & 34.7 & 3476.5 & 40.5 & 9630.2 \\
\hline 1-008A & 1258.7 & 4.1 & 2.5 & 12.5 & 2.66 & 1.71 & 35.6 & 3255.4 & 38.8 & 9010.6 \\
\hline 1-009A & 1258.7 & 2.4 & 2.4 & 7.1 & 2.64 & 1.69 & 36.2 & 4547.5 & 38.5 & 8680.5 \\
\hline 1-011A & 1259.1 & 2.4 & 2.5 & 7.4 & 2.63 & 1.71 & 35.2 & 3561.6 & 37.8 & 8384.5 \\
\hline 1-014A & 1260.1 & 4.8 & 2.5 & 14.9 & 2.64 & 1.70 & 35.6 & 3127.8 & 38.5 & 8207.3 \\
\hline $1-020 \mathrm{~A}$ & 1260.9 & 4.4 & 2.5 & 13.6 & 2.63 & 1.68 & 35.9 & 3703.2 & 38.4 & 7809.3 \\
\hline $1-021 \mathrm{~A}$ & 1260.9 & 2.4 & 2.5 & 7.7 & 2.63 & 1.70 & 35.3 & 3224.1 & 40.6 & 7626.4 \\
\hline $1-022 \mathrm{~A}$ & 1261.2 & 3.8 & 2.4 & 10.8 & 2.62 & 1.63 & 38.0 & 3943.8 & 35.7 & 6999.1 \\
\hline $1-024 \mathrm{~A}$ & 1262.1 & 2.4 & 2.4 & 6.6 & 2.62 & 1.64 & 37.6 & 5482.5 & 38.0 & 6991.7 \\
\hline $1-025 \mathrm{~A}$ & 1262.5 & 2.3 & 2.4 & 6.0 & 2.62 & 1.60 & 39.2 & 3598.3 & 36.4 & 6714.7 \\
\hline $1-026 \mathrm{~A}$ & 1262.6 & 2.3 & 2.4 & 6.1 & 2.65 & 1.56 & 39.8 & 6774.4 & 39.4 & 5987.7 \\
\hline $1-027 \mathrm{~A}$ & 1262.7 & 4.3 & 2.4 & 12.2 & 2.63 & 1.65 & 37.2 & 4768.4 & 37.5 & 5908.4 \\
\hline $1-028 \mathrm{~A}$ & 1262.7 & 2.3 & 2.4 & 6.7 & 2.62 & 1.67 & 36.3 & 4175.8 & 37.9 & 5846.8 \\
\hline 1-029A & 1262.9 & 2.2 & 2.4 & 6.4 & 2.62 & 1.66 & 36.5 & 5265.7 & 35.8 & 5826.4 \\
\hline 1-030A & 1263.4 & 2.2 & 2.4 & 6.6 & 2.61 & 1.75 & 33.1 & 3504.3 & 36.3 & 5814.1 \\
\hline 1-031A & 1263.6 & 4.4 & 2.4 & 11.8 & 2.63 & 1.57 & 40.2 & 3725.6 & 35.5 & 5783.7 \\
\hline $1-032 \mathrm{~A}$ & 1263.6 & 2.0 & 2.4 & 5.6 & 2.61 & 1.65 & 37.0 & 3179.3 & 36.6 & 5488.3 \\
\hline 1-033A & 1263.7 & 4.9 & 2.4 & 13.3 & 2.62 & 1.59 & 39.3 & 3708.6 & 34.9 & 2458.4 \\
\hline $1-035 \mathrm{~A}$ & 1264.1 & 3.8 & 2.4 & 11.0 & 2.62 & 1.75 & 33.3 & 3365.7 & 34.2 & 2376.9 \\
\hline $1-036 \mathrm{~A}$ & 1264.3 & 2.1 & 2.5 & 6.2 & 2.62 & 1.60 & 39.1 & 4437.4 & 35.4 & 2366.5 \\
\hline
\end{tabular}




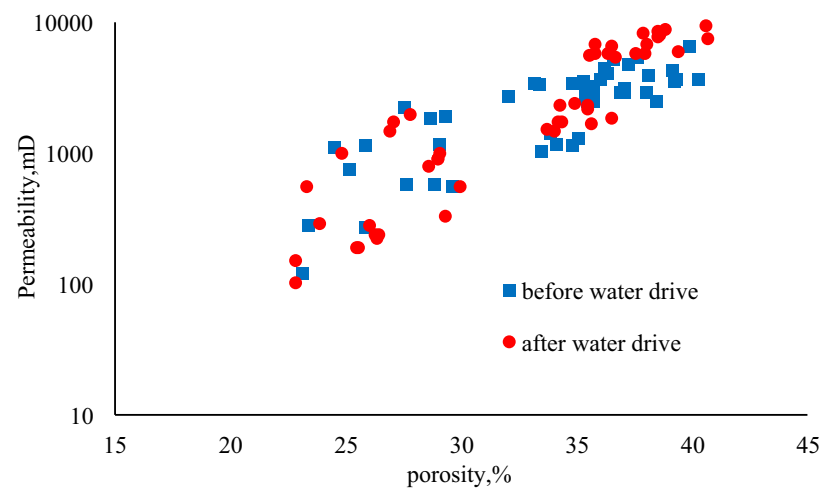

a Changes of porosity and permeability before and after water flooding

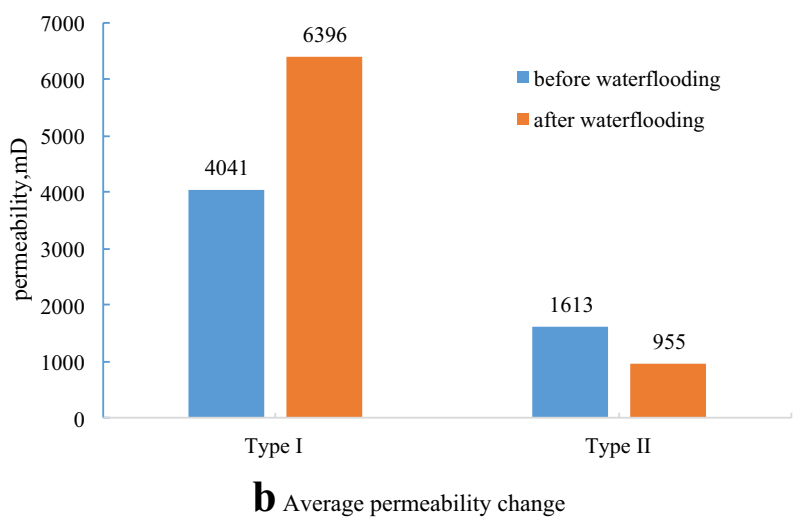

Fig. 8 Comparison of porosity and permeability test data before and after water flooding. a Changes of porosity and permeability before and after water flooding; $\mathbf{b}$ average permeability change

pore throats' shape decrease irregular. After waterflooding of type II reservoir, the porosity and pore diameter of the core become smaller and smaller after waterflooding, and the shape of the throat is curved primarily and flaky. It can be seen that the pore volume is reduced due to long-term waterflooding, particles are accumulated in the throat of tiny pores, and partial pore throat plugging reduces the overall permeability of the core. With the decrease in the initial permeability, the average pore throat radius becomes smaller, and the probability of plugging and the degree increase further.

\section{Changes in clay minerals in the reservoir}

The observation results of clay minerals in reservoir rocks before and after water flooding show that: after long-term water flooding, the clay minerals in pores and on the surface of mineral particles of type I reservoir decrease significantly; Before waterflooding, kaolinite in sandstone pores occurs in aggregate form with complete crystal form. After waterflooding, kaolinite in pores is dispersed chiefly, which is easy to be washed out by water flow, resulting in the decrease in clay mineral content in pores (see Fig. 11). The clay mineral content of type II reservoir is relatively high. After long-term water flooding, the clay mineral content of the reservoir changes little. The clay mineral content of the relatively coarse pore throat diameter decreases to a certain extent, but the clay mineral content of the relatively fine pore throat diameter changes little or even increases; Before water flooding, illite separated pore throats in filamentous form. After water flooding, kaolinite and illite crystals had insufficient deformation, migrated after hydration and expansion, and finally accumulated in the small part of pore throats, or even blocked the pore throats by bridging (Xiaofan et al. 2011). SEM image analysis showed that cement content was high, feldspar particles dissolved, kaolinite filled intergranular pores, and flocculent illite wrapped the surface of particles (see Fig. 12).

\section{Reservoir wettability change}

We can get the relative permeability under high multiple displacements (see Fig. 13). According to the relevant knowledge of reservoir physics, we can know that the permeability point can determine the reservoir's wettability. The reservoir type can be effectively analyzed by comparing it with the water saturation value of 50\% (Feng et al. 2017; Yubin et al. 2021). When the interface condition in the pore space of reservoir rock changes, the rock's wettability also changes in varying degrees. The change of wettability before and after waterflooding in different reservoirs in the $\mathrm{X}$ reservoir has different regularity.

After long-term water flooding, the oil-friendly clay minerals and formation particles in the reservoir decrease, the particle surface becomes clean, the pore throat radius increases, the rock adsorption capacity decreases, and the rock wettability changes from weak hydrophilic to strong hydrophilic (Yunlai et al. 2020; Hakiki et al. 2015). Thus, the content of clay minerals in the type I reservoir decreased significantly, the radius of the pore throat increased, and the wettability changed more obviously; the content of clay minerals in the type II reservoir and the radius of the pore throat changed minor, and the wettability changed relatively less.

It can be seen from the morphology of the phase permeability that with the increase in displacement multiple, the isotonic point of the phase permeability tends to move to the right, so it can be inferred that the wettability of the reservoir rock changes gradually. The water phase permeability shows that the water phase permeability after high multiple displacements is different from conventional displacement. After multiple high displacements, the reservoir's physical properties change, and there may be high permeability bands. Once the high permeability flow band appears, the channel's main flow is water phase flow, and the relative permeability of the oil phase is relatively low. At

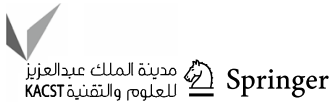


Table 3 Changes of physical properties of type II reservoir before and after waterflooding

\begin{tabular}{|c|c|c|c|c|c|c|c|c|c|c|}
\hline \multirow[t]{2}{*}{ Sample ID } & \multirow[t]{2}{*}{ Depth, m } & \multirow[t]{2}{*}{ Length, $\mathrm{cm}$} & \multirow[t]{2}{*}{ Diameter, $\mathrm{cm}$} & \multirow{2}{*}{$\begin{array}{l}\text { Grain } \\
\text { volume, } \\
\mathrm{cm}^{3}\end{array}$} & \multirow{2}{*}{$\begin{array}{l}\text { Grain } \\
\text { density, g/ } \\
\mathrm{cm}^{3}\end{array}$} & \multirow{2}{*}{$\begin{array}{l}\text { Rock } \\
\text { density, g/ } \\
\mathrm{cm}^{3}\end{array}$} & \multicolumn{2}{|c|}{ Before waterflooding } & \multicolumn{2}{|c|}{ After waterflooding } \\
\hline & & & & & & & Porosity, \% & Kair, mD & Porosity, \% & Kair, mD \\
\hline $1-001 \mathrm{~A}$ & 1256.9 & 3.4 & 2.4 & 10.2 & 2.65 & 1.75 & 34.0 & 1211.5 & 35.4 & 2197.8 \\
\hline $1-002 \mathrm{~A}$ & 1257.5 & 2.1 & 2.4 & 5.9 & 2.65 & 1.63 & 38.4 & 2537.5 & 27.7 & 2028.1 \\
\hline $1-003 \mathrm{~A}$ & 1257.9 & 2.0 & 2.4 & 6.1 & 2.65 & 1.75 & 33.8 & 1430.7 & 36.4 & 1878.2 \\
\hline $1-004 \mathrm{~A}$ & 1258.1 & 4.1 & 2.4 & 12.2 & 2.68 & 1.74 & 35.0 & 1337.6 & 34.1 & 1781.9 \\
\hline $1-005 \mathrm{~A}$ & 1258.2 & 2.5 & 2.4 & 7.5 & 2.67 & 1.74 & 34.8 & 1143.7 & 27.0 & 1756.7 \\
\hline $1-006 \mathrm{~A}$ & 1258.5 & 2.4 & 2.4 & 6.7 & 2.64 & 1.66 & 37.0 & 2980.7 & 34.3 & 1738.5 \\
\hline $1-010 \mathrm{~A}$ & 1259.1 & 2.9 & 2.5 & 9.9 & 2.64 & 1.92 & 27.4 & 2256.5 & 35.6 & 1730.2 \\
\hline $1-012 \mathrm{~A}$ & 1259.4 & 4.8 & 2.5 & 14.7 & 2.67 & 1.72 & 35.4 & 2555.6 & 33.7 & 1546.3 \\
\hline $1-013 \mathrm{~A}$ & 1259.6 & 2.4 & 2.5 & 8.1 & 2.65 & 1.80 & 32.0 & 2759.3 & 33.9 & 1516.8 \\
\hline $1-015 \mathrm{~A}$ & 1260.3 & 4.4 & 2.5 & 13.4 & 2.63 & 1.70 & 35.3 & 2657.7 & 26.8 & 1507.2 \\
\hline 1-016A & 1260.5 & 2.4 & 2.5 & 7.3 & 2.62 & 1.65 & 36.9 & 2981.4 & 29.0 & 1017.0 \\
\hline $1-017 \mathrm{~A}$ & 1260.5 & 2.4 & 2.4 & 7.4 & 2.63 & 1.75 & 33.4 & 1059.5 & 24.7 & 999.0 \\
\hline 1-018A & 1260.6 & 2.4 & 2.5 & 7.8 & 2.63 & 1.80 & 29.6 & 568.5 & 28.9 & 934.2 \\
\hline 1-019A & 1260.7 & 2.3 & 2.5 & 7.4 & 2.63 & 1.69 & 35.6 & 2714.6 & 28.9 & 910.1 \\
\hline $1-023 \mathrm{~A}$ & 1261.6 & 4.2 & 2.4 & 12.3 & 2.63 & 1.69 & 35.7 & 2492.9 & 28.5 & 811.3 \\
\hline $1-034 \mathrm{~A}$ & 1263.9 & 2.2 & 2.4 & 6.1 & 2.61 & 1.62 & 38.0 & 2971.1 & 23.2 & 571.8 \\
\hline $1-037 \mathrm{~A}$ & 1599.0 & 5.1 & 2.4 & 17.4 & 2.64 & 1.98 & 25.0 & 759.4 & 29.9 & 568.0 \\
\hline $1-038 \mathrm{~A}$ & 1599.0 & 2.4 & 2.5 & 8.8 & 2.60 & 1.96 & 24.4 & 1131.7 & 29.2 & 338.9 \\
\hline 1-039A & 1599.8 & 4.8 & 2.4 & 15.9 & 2.62 & 1.85 & 29.3 & 1923.4 & 23.8 & 296.9 \\
\hline $1-040 \mathrm{~A}$ & 1600.1 & 4.7 & 2.5 & 15.8 & 2.60 & 1.86 & 28.6 & 1885.3 & 26.0 & 287.0 \\
\hline 1-041A & 1601.5 & 4.6 & 2.5 & 18.3 & 2.62 & 2.09 & 23.1 & 121.2 & 26.2 & 245.6 \\
\hline $1-042 \mathrm{~A}$ & 1602.1 & 2.4 & 2.4 & 8.8 & 2.60 & 1.99 & 23.3 & 281.5 & 26.4 & 242.0 \\
\hline $1-043 \mathrm{~A}$ & 1603.8 & 4.6 & 2.5 & 16.3 & 2.61 & 1.89 & 27.5 & 579.7 & 26.2 & 230.5 \\
\hline $1-044 \mathrm{~A}$ & 1604.5 & 2.4 & 2.5 & 8.7 & 2.60 & 1.93 & 25.8 & 274.0 & 25.5 & 195.6 \\
\hline $1-045 \mathrm{~A}$ & 1604.5 & 4.1 & 2.5 & 14.6 & 2.60 & 1.85 & 28.7 & 586.7 & 25.4 & 195.5 \\
\hline 1-046A & 1604.6 & 2.3 & 2.4 & 7.7 & 2.60 & 1.85 & 29.0 & 1187.3 & 22.7 & 153.1 \\
\hline $1-047 \mathrm{~A}$ & 1604.6 & 2.8 & 2.5 & 9.8 & 2.61 & 1.94 & 25.8 & 1170.3 & 22.7 & 103.1 \\
\hline
\end{tabular}

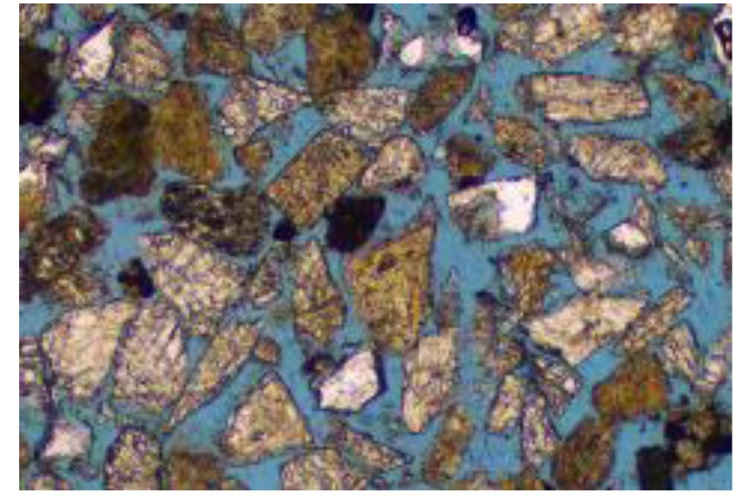

a before waterflooding

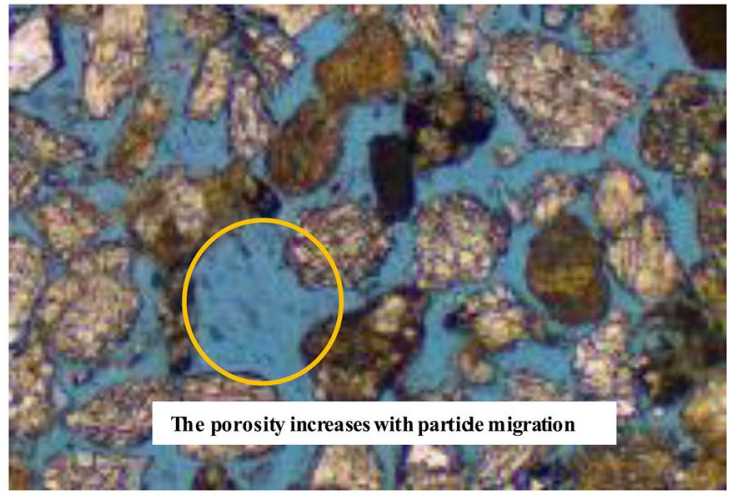

b after waterflooding

Fig. 9 Cast thin-section photographs of samples before and after waterflooding in type I reservoir, 50 times. a before waterflooding; $\mathbf{b}$ after waterflooding 


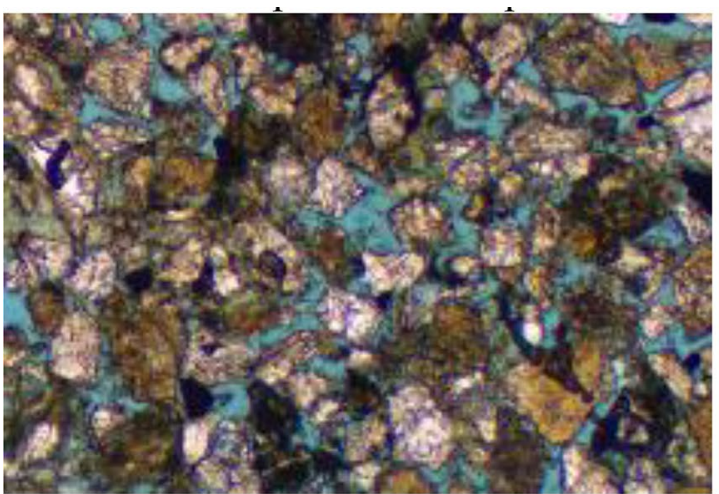

a before waterflooding

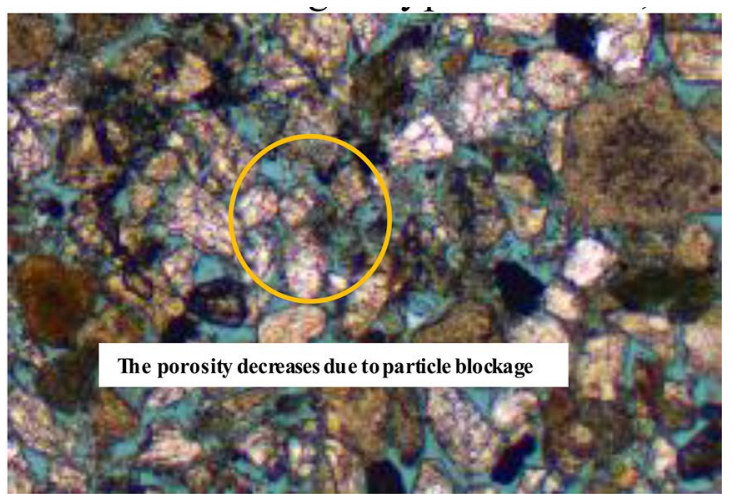

b after waterflooding

Fig. 10 Thin-section photographs of casting samples before and after waterflooding in type II reservoir, 50 times. a before waterflooding; $\mathbf{b}$ after waterflooding

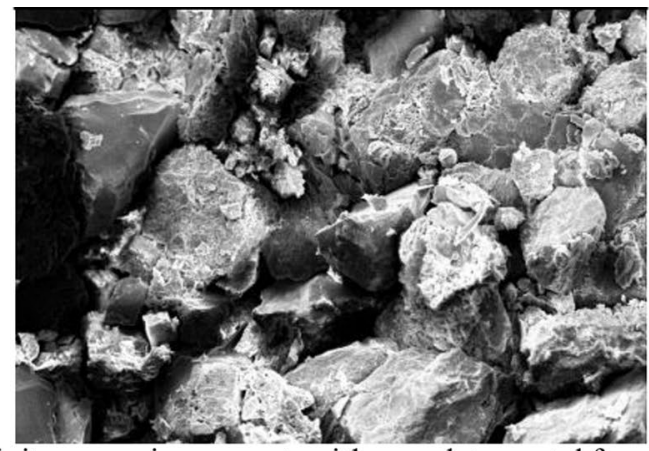

Kaolinite occurs in aggregate with complete crystal form. a before waterflooding

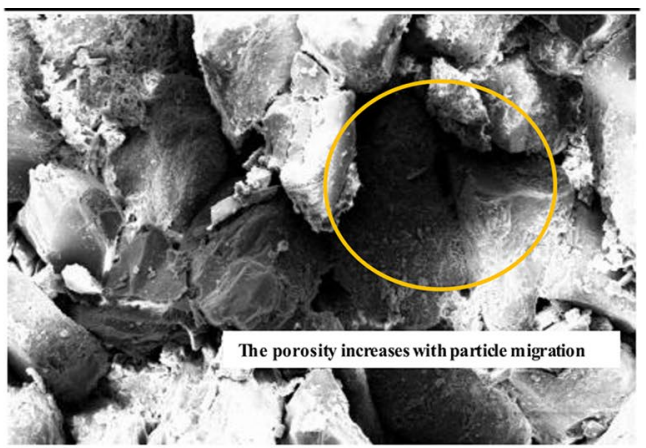

b after waterflooding

Fig. 11 SEM photographs of reservoir samples before and after waterflooding in type I reservoir, 1000 times; $\mathbf{a}$ before waterflooding; $\mathbf{b}$ after waterflooding

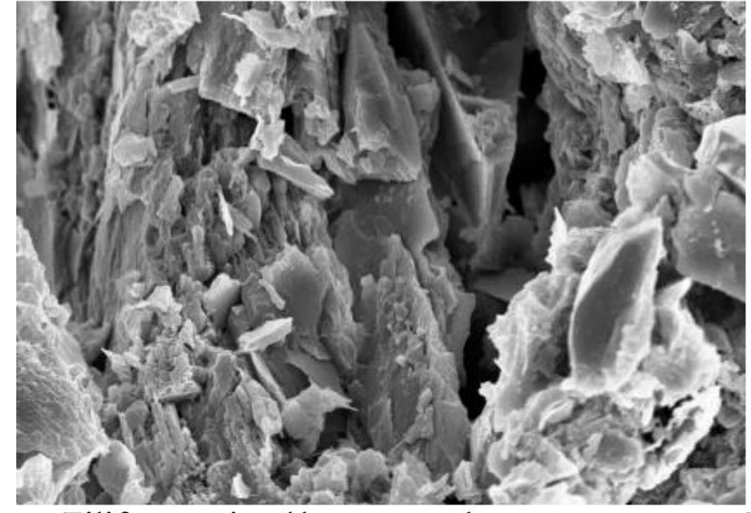

Filiform mixed layer pore throat

a before waterflooding

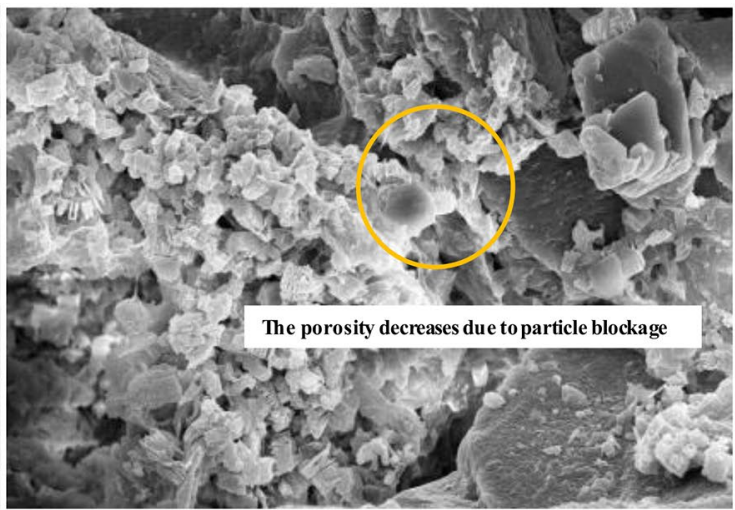

Filling intergranular pores with scaly kaolinite and filiform smectite mixed layers

b after waterflooding

Fig. 12 SEM photographs of reservoir samples before and after waterflooding in type I reservoir, 1000 times. a Before waterflooding; $\mathbf{b}$ after waterflooding

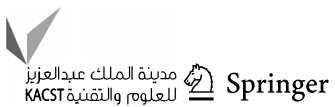



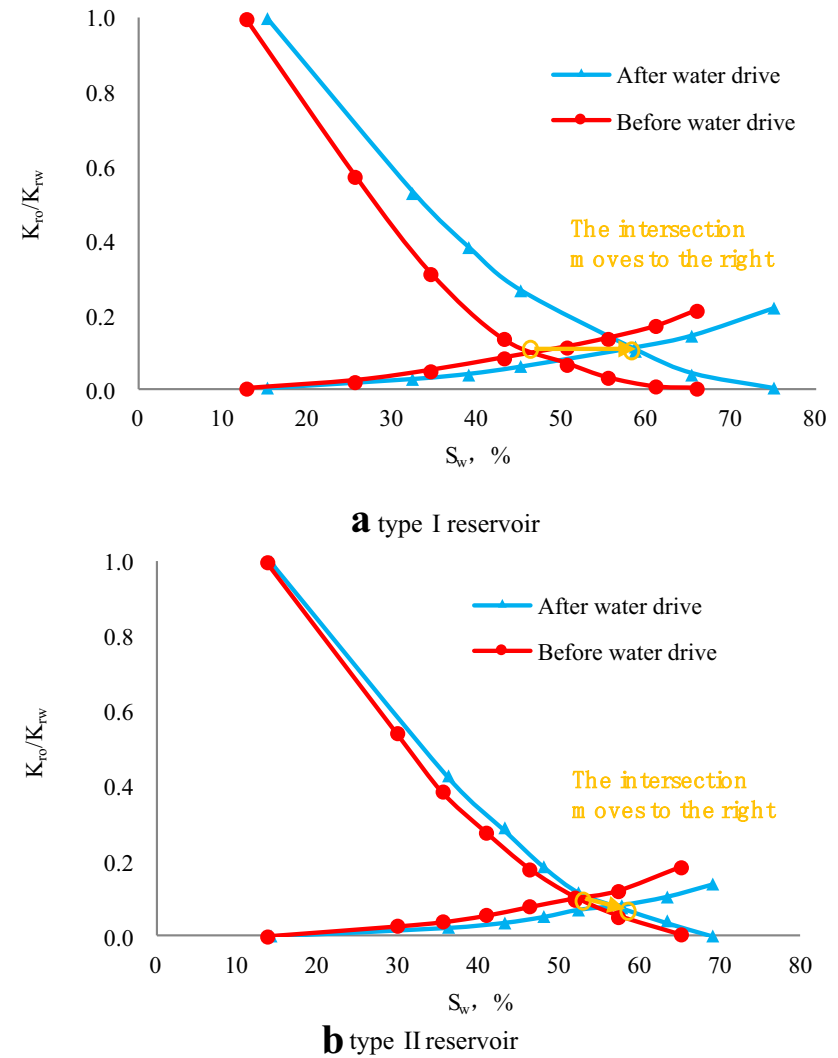

Fig. 13 Change mechanism of physical properties. a Type I reservoir; b type II reservoir

this time, the relative permeability of the water phase can be approximately absolute. In the later stage of displacement, the morphology of water phase permeability is relatively gentle, which leads to the change of adsorption and desorption of polar substances on the surface of the reservoir. It is revealed that the isotonic point moves to the right with the increase in water drive multiple, and the wettability changes from oil affinity to water affinity. According to the change of isotonic point, the reservoir under 30PV is oil-wet, and the corresponding water saturation at $2000 \mathrm{PV}$ is more excellent than $50 \%$, which is water wet, that is to say, under the condition of high multiple water drive, the wettability of reservoir changes.

\section{Conclusions}

In this study, through the experiments of oil displacement efficiency under different permeability, viscosity, and injection intensity, we get the following conclusions:

1. The range of recovery under $2000 \mathrm{PV}$ water drive of core in reservoir $\mathrm{X}$ is $62.5 \%-77.5 \%, 34.2 \%-22.0 \%$ higher than that under $98 \%$ water cut.
2. With $98 \%$ water cut, the recovery degree and 2000PV recovery degree decrease with the decrease in fluidity, a power index relationship with crude oil viscosity.

3. Under the same viscosity of crude oil, the recovery degree in the anhydrous period, the recovery degree in 98\% water cut, and the logarithm of ultimate recovery factor and permeability have a specific positive correlation. However, when the physical properties are similar, the recovery degree in the anhydrous period, the recovery degree in $98 \%$ water cut, and the logarithm of ultimate recovery factor and crude oil viscosity have a significant negative correlation.

4. When the core's physical properties are similar, the recovery degree and injection strength have an absolute negative correlation in the anhydrous period. Conversely, the recovery degree and 2000PV recovery degree have an absolute positive correlation with injection strength when the water content is $98 \%$.

5. After high power water flooding, the average porosity of the core decreases. The thin casting section shows that the sample's face rate and pore diameter become smaller after water flooding, and the throat shape is curved primarily. The scanning electron microscope shows that the accumulation of clay minerals occurs in the reservoir's pore throat after waterflooding.

6. After long-term waterflooding, the permeability changes differently in different porosity ranges. The reservoirs with porosity more significant than $30 \%$ are the reservoir's main reservoirs, with strong seepage capacity. After long-term scouring of formation water, the permeability further increases, while the permeability of the reservoirs with porosity less than $30 \%$ decreases.

7. After a long-term water drive, the clay minerals in the pores and on the surface of mineral particles in a type I reservoir are reduced; after a long-term water drive, the content of clay minerals in a type II reservoir is relatively high. After a long-term water drive, the content of clay minerals in the reservoir changes slightly, and the clay minerals in the position with a relatively coarse pore throat diameter decrease to a certain extent, but the clay minerals in the position with a relatively subtle pore throat diameter change little, even there has been an increase.

8. After long-term water flooding, the oil-friendly clay minerals and formation particles in the reservoir decrease, the particle surface becomes clean, the pore throat radius increases, the rock adsorption capacity decreases, and the rock wettability changes from weak hydrophilic to strong hydrophilic. The content of clay minerals in the type I reservoir decreased significantly, the radius of the pore throat increased, and the wettability changed more obviously; the content of clay minerals in the type II reservoir and the radius of the pore throat 
changed minor, and the wettability changed relatively less. The analysis shows that the residual oil saturation decreases with the increase in water drive multiple.

Funding The project is supported by the National Science and Technology Major Project during the 13th Five-year Plan Period "Bohai Oilfield Efficient Development Demonstration Project" (Number 2016ZX05058). The funders had no role in study design, data collection, analysis, decision to publish, or manuscript preparation.

Open Access This article is licensed under a Creative Commons Attribution 4.0 International License, which permits use, sharing, adaptation, distribution and reproduction in any medium or format, as long as you give appropriate credit to the original author(s) and the source, provide a link to the Creative Commons licence, and indicate if changes were made. The images or other third party material in this article are included in the article's Creative Commons licence, unless indicated otherwise in a credit line to the material. If material is not included in the article's Creative Commons licence and your intended use is not permitted by statutory regulation or exceeds the permitted use, you will need to obtain permission directly from the copyright holder. To view a copy of this licence, visit http://creativecommons.org/licenses/by/4.0/.

\section{References}

Anderson WG (1987) Wettability Literature Survey - Part 6: The Effect of Wettability on Waterflooding. JPT, Dec:1605-1622

Bolin L (2003) Study on micro water flooding mechanism and influencing water flooding efficiency factors in Chenbao oilfield. Subei Basin Pet Exp Geol 25(2):178-181

Daopin Li (1997) Development of low permeability sandstone oilfield. Petroleum Industry Press, Beijing, pp 66-87

Donaldson EC, Thomas RD (1971) Microscopic Observations of Oil Displacement in Water Wet and Oil Wet Systems. SPE3555

Feng W, Yuelin Li, Xuan D et al (2017) New understanding and application of oil displacement efficiency in Wenchang A oilfield. Pet Geol Eng 31(4):74-76

Guo SC, Yongli G, Guangrong L et al (2004) Experimental study on improving water flooding efficiency of ultra-low permeability reservoir. J xi' an Pet Univ (nat Sci Edit) 19(3):23-25

Hakiki F, Maharsi DA, Marhaendrajana T (2015) Surfactant-polymer core flood simulation and uncertainty analysis derived from laboratory study. J Eng Technol Sci 47(6):706-725

Jadhunandan PP, Morrow NR (1995) Effect of Wettability on Waterflood Recovery for Crude Oil/ Brine/ Rock Systems. SPE Reservoir Engineering, Feb:40-46

Jienian Y (1998) Influence of reservoir rock wettability on oil displacement efficiency during water injection. J Pet Univ (nat Sci EdiT) 22(3):43-46

Min X (2003) pore structure and oil displacement efficiency of Panhe fault block. Pet Nat Gas Geol 24(1):42-44

Morrow NR (1990) Wettability and Its Effect on Oil Recovery, JPT, Dec: 1476-1484

Nailin T, Lihua Z (1997) Laboratory experimental study on oil displacement efficiency of high pour point oil. Pet Geol DeveloP Daqing 16(3):53-55

Pingping S (2000) Theory and practice of oil-water movement in porous media. Petroleum Industry Press, Beijing
Puhua Y, Fangtian Ni (1998) Core analysis translation set. Petroleum Industry Press, Beijing

Qitai Yu, Ming Z, Zhifang L (1989) Study on oil displacement efficiency and sweep efficiency of water drive sandstone (1). Pet Explor Dev 16(2):48-52

Qiuxuan He, Yongli G (1996) Study on microscopic oil displacement efficiency of reservoirs in Shenyang oilfield. J Southwest Pet Univ 18(2):20-24

Xiaojuan R, Zhihao Q, Chengen S et al (2005) Microscopic water flooding characteristics of ultra-low permeability and weak oil-bearing reservoirs in Xifeng Oilfield. J Northwest Univ (nat Sci Edit) 35(6):766-769

Renxiong Z (1995) Influence of displacement conditions on water displacement efficiency of glutenite reservoir. Henan Pet 9(4):32-37

Shaodong Z (2002) Reservoir microstructure and its effect on oil displacement efficiency in Gudao Oilfield. J Pet Univ (nat Sci) 26(3):47-54

Wei S, Xiaoyan Fu (1999) Water drive efficiency and influencing factors of Yan'an Formation reservoir in Jiyuan. Pet Nat Gas Geol 20(1):26-29

Wensheng Lu (2003) Study on reservoir displacement characteristics of Suizhong 36-1 oilfield. Offshore Oil and Gas Geol China 17(3):181-184

Xianmin Z, Qigui Ma, Shengjia Xu et al (1994) Influence of reservoir wettability on water flooding efficiency. Daqing Pet Geol Develop 13(1):70-71

Xiaofan C, Feng L, Bo W et al (2011) Variation of permeability of high porosity and high permeability reservoir under long-term scouring condition. Daqing Pet Geol Develop 30(6):84-87

Yanzhang H (1998) Percolation mechanism of low permeability reservoir. Petroleum Industry Press, Beijing

Yarveicy H, Javaheri A (2019) Application of Lauryl Betaine in enhanced oil recovery: A comparative study in micromodel. Petroleum 5:123-127

Yarveicy H, Habibi A, Pegov S et al (2018) Enhancing oil recovery by adding surfactants in fracturing water: a montney case study. SPE-189829-MS

Yongli G (1996) Study on micro displacement efficiency of Leng43 conglomerate heavy oil reservoir in Liaohe Oilfield. J xi' an Pet Univ 11(4):35-36

Youfu W, Ying B (1999) Relationship between pore structure and oil displacement efficiency of reservoir rocks. Henan Pet 25(1):23-25

Yubin B, Jingzhou Z, Delin Z et al (2021) Pore structure and control on reservoir quality in tight sandstones: a case study of the Chang 6 member of the Upper Triassic Yanchang Formation in the Jingbian oilfield in the Ordos Basin, China. J Pet Explor Product Technol 11:171-189

Yunlai Z, Jilei Z, Yanbin Z et al (2020) Study on the development law of water flooding in offshore loose sandstone reservoir at high water cut stage. J Petrochem Univ 33(5):30-35

Yushuang Z, Qu Z, Kong L et al (1999) Influenced the oil displacement efficiency of Chang 6 and Chang 2 reservoirs in Jing' an oilfield. Pet Nat Gas Geol 20(4):333-335

Zhetan L, Yuncheng W (1986) Pore structure of oil and gas reservoirs. Science Press, Beijing

Zhong C (2000) Relationship between reservoir pore structure and oil displacement efficiency. Pet Explor Dev 27(6):45-47

Publisher's Note Springer Nature remains neutral with regard to jurisdictional claims in published maps and institutional affiliations. 